\title{
Treating renal anaemia with recombinant human erythropoietin: practical guidelines and a clinical algorithm
}

\author{
Iain C Macdougall, R David Hutton, Ivor Cavill, Gerald A Coles, John D Williams
}

\begin{abstract}
Treatment with erythropoietin is highly effective and beneficial if given with care. In view of its cost, however, it is essential to exclude and treat other causes of anaemia before considering using this hormone. After treatment is started the important points for success are regular review of iron availability state combined with a slow correction of the anaemia. Failure of response requires a thorough search for a possible cause, which should be corrected before considering an increased dose of the hormone. Regular monitoring for potential complications, particularly a rise in blood pressure, is required.
\end{abstract}

\section{Introduction}

Recombinant human erythropoietin has been proved beneficial in treating renal anaemia, ${ }^{1-4}$ and clinical trials have indicated an acceptable degree of safety. ${ }^{5.9}$ It has recently been licensed for use in the United States and several European countries, and is expected to receive a product licence in the United Kingdom in the near future. The drug will soon be widely available, and there is a need for practical guidelines to ensure that patients receive maximum benefit with the least risk and greatest cost efficiency.

From our own experience in treating 42 patients and from published studies we have compiled recommendations together with a clinical algorithm as a guide for the management of patients being treated with erythropoietin. This article considers which patients should be treated, the optimum starting dose and route of administration, the monitoring of iron state, target haemoglobin concentration, the rate of response, and the investigation of an impaired response, as well as potential complications.

\section{Institute of Nephrology, University of Wales}

College of Medicine, Royal Infirmary, Cardiff CF2 1SZ Iain C Macdougall, MRCP, clinical research fellow Gerald A Coles, MRCP, consultant physician John D Williams, FRCP, senior lecturer

Department of Haematology, University of Wales College of Medicine, Royal Infirmary, Cardiff CF2 1SZ

R David Hutton, MRCPATH, senior lecturer

Ivor Cavill, FRCPATH, senior lecturer

Correspondence to: Dr Macdougall

\section{Which patients should receive erythropoietin?}

It remains uncertain exactly how many patients receiving dialysis would benefit from treatment with erythropoietin, but estimates of $50-75 \%$ have been made.$^{23}$ As the treatment is expensive and long term it is important to be selective in its use.

There is often a rise in packed cell volume after dialysis is started, particularly with continuous ambulatory peritoneal dialysis, ${ }^{10}{ }^{11}$ and it is therefore wise to wait at least three months after starting renal replacement therapy before considering erythropoietin. Furthermore, if the patient is likely to receive a live donor transplant in the near future erythropoietin treatment might not be warranted. Patients with a haemoglobin concentration $>100 \mathrm{~g} / \mathrm{l}$ are unlikely to have a noticeable improvement in wellbeing and have a higher chance of side effects because the viscosity of whole blood rises rapidly with higher packed cell volume. ${ }^{12-14}$ Thus only uraemic patients with haemo- globin concentrations $<100 \mathrm{~g} / \mathrm{l}$ should be considered for treatment.

It is important to exclude other causes of anaemia such as haematinic deficiency, blood loss, haemolysis, infection, aluminium toxicity, and malignancy. Any such disorder should be corrected and the haemoglobin response assessed before treatment with erythropoietin is considered. In the absence of any other cause patients with a haemoglobin concentration $<80 \mathrm{~g} / \mathrm{l}$ will almost certainly benefit from treatment. Those with a haemoglobin concentration of $80-100 \mathrm{~g} / \mathrm{l}$ who have symptoms referable to their anaemia, particularly angina, should also be offered the hormone.

Whether patients who are at end stage renal failure should be treated before starting dialysis is still unclear. There is a theoretical risk that raising the packed cell volume would, by increasing viscosity or reducing renal plasma flow, or both, impair renal perfusion and thus lead to a more rapid decline in renal function: ${ }^{15}$ Studies to date suggest, however, that treatment with erythropoietin has no effect on the clinical course of the uraemia. ${ }^{16-18}$ In our experience, patients with a haemoglobin concentration of $<80 \mathrm{~g} / 1$ usually have either end stage renal failure or another condition contributing to their anaemia, such as myeloma. Treatment should therefore normally be reserved for patients with symptomatic anaemia who are unlikely to need to start long term dialysis within the next three months.

Whether treatment with erythropoietin will be effective in patients with a multifactorial cause for their anaemia-for example, uraemia and rheumatoid arthritis - is uncertain. Finding an inappropriately low serum erythropoietin concentration for the degree of anaemia ${ }^{19}$ could be an indication for a trial of treatment, but the response may be impaired by the underlying chronic disease.

\section{Monitoring iron state}

It is important to determine clearly the baseline iron state of any patient being considered for erythropoietin treatment for two reasons. Firstly, if a patient is iron deficient then some improvement in haemoglobin concentration can be expected to occur with iron treatment alone, either oral ${ }^{20}$ or intravenous. ${ }^{21}$ The substantial. As a result, treatment with erythropoietin should be withheld until it is clear that the patient is not iron deficient or until a deficiency has been fully treated, as evidenced by a stable haemoglobin concentration. If the serum ferritin concentration is $<15 \mu \mathrm{g} / \mathrm{l}$ the patient is iron deficient. Higher concentrations of serum ferritin may be found in iron deficient patients - for example, in conditions causing hepatocyte dysfunction or greatly increased iron resorption from extravasated blood. In these circumstances, the serum ferritin concentration may be raised out of proportion potential cost saving of such simple treatment could be 
to the iron stores. There may also be a short term increase in the saturation of transferrin. If there is doubt about the patient's true iron state a therapeutic trial of oral or intravenous iron should be given for a minimum of four weeks. If there is any response during this period then treatment with erythropoietin should be postponed until a new stable concentration of haemoglobin is achieved. At this point the need for the hormone should be reassessed. In all cases it is important to remember that infection or active inflammatory processes, including peritonitis in patients receiving continuous ambulatory peritoneal dialysis, may prevent a response to treatment with iron.

It is also important to estimate the baseline iron state in order to determine whether there is enough readily available iron to meet the anticipated demand. The advent of erythropoietin has resulted in an unprecedented and potent therapeutic stimulus to erythropoiesis, and it has become apparent that large quantities of iron are used in this process. Thus, patients who are iron replete before starting the hormone can rapidly become deficient under the influence of this treatment. ${ }^{126223}$ This may occur in the presence of a normal serum ferritin concentration (suggesting adequate iron stores) and stainable iron in the marrow, and the problem seems to be a limitation in the rate of iron supply - that is, the stores are unable to release iron fast enough to meet the demand.

A rise of $10 \mathrm{~g} / \mathrm{l}$ in the circulating haemoglobin concentration uses $150 \mathrm{mg}$ of storage iron (equivalent to nearly $20 \mu \mathrm{g} / \mathrm{l}$ of serum ferritin). ${ }^{24}$ Thus for an anticipated haemoglobin rise of $50 \mathrm{~g} / 1$ after treatment with erythropoietin, the absolute minimum requirements would be $750 \mathrm{mg}$ of storage iron $(100 \mu \mathrm{g} / \mathrm{l}$ serum ferritin). Patients with starting serum ferritin concentrations $<100 \mu \mathrm{g} / \mathrm{l}$ are therefore highly likely to develop functional iron deficiency and will require intensive iron supplementation, almost certainly in the form of parenteral iron. A nomogram has been devised for estimating the projected iron deficit based on the initial haemoglobin and serum ferritin concentrations and assuming a target haemoglobin concentration of $116 \mathrm{~g} / \mathrm{l}^{22}$; these authors also showed that oral iron supplementation is unlikely to keep pace with the demand during the early phase of treatment with erythropoietin. ${ }^{22}$

Patients with initial serum ferritin concentrations $>100 \mu \mathrm{g} / \mathrm{l}$ may also develop functional iron deficiency," $"$ which is best detected from changes in the percentage saturation of transferrin with iron. If this falls below $20 \%$ then it is likely that the available iron supply to the erythron is inadequate. ${ }^{122223}$ Bainton and Finch have shown that functional iron deficiency occurs once the transferrin saturation is reduced to below $16 \%$. $^{5}$ Thus if the transferrin saturation becomes less than $20 \%$ at any stage of erythropoietin treatment, parenteral iron should be given. The figure presents an algorithm for managing patients being treated with erythropoietin, with particular emphasis on monitoring iron state and the need for iron supplementation.

\section{Starting dose of erythropoietin and route of administration}

Most experience of treatment with erythropoietin is with intravenous therapy in patients receiving haemodialysis, and one of the earliest studies showed that there was a dose dependent rate of response to the hormone. ${ }^{6}$ It has become increasingly apparent, however, that the risk of side effects such as severe hypertension and thrombotic complications is lessened when the rise in haemoglobin concentration is about 10 $\mathrm{g} / \mathrm{l} / \mathrm{month}$. Erythropoietin is usually prescribed in doses of $100-200 \mathrm{U} / \mathrm{kg} /$ week for patients receiving haemodialysis, divided into two or three intravenous doses. A similar intravenous dosage regimen has been used with good effect in patients not yet receiving dialysis. ${ }^{16-18}$

The intravenous route is clearly impractical for chronic use in patients having continuous ambulatory peritoneal dialysis who have no ready vascular access. The intraperitoneal and subcutaneous routes are obvious alternatives. In patients receiving continuous ambulatory peritoneal dialysis the bioavailability of erythropoietin given subcutaneously in a single dose was found to be seven times greater than when it was given intraperitoneally but was still only $22 \% .^{26}{ }^{27}$ Nevertheless, Frenken et al used the intraperitoneal route for treating five patients receiving continuous ambulatory peritoneal dialysis and obtained an effective clinical response with a dosage of $300 \mathrm{U} / \mathrm{kg} /$ week (three separate doses).$^{28}$ We showed a similar response in nine patients receiving continuous ambulatory peritoneal dialysis $^{29}$ and 12 . patients receiving haemodialysis treated with only $120 \mathrm{U} / \mathrm{kg} /$ week (two separate doses) given subcutaneously. ${ }^{30}$ This dosage achieved a similar correction of anaemia to that obtained with $240 \mathrm{U} / \mathrm{kg} /$ week (two doses) given intravenously to 10 patients receiving haemodialysis..$^{30}$ The overall rate of response, however, was slightly slower. Bommer et al showed that a $50 \%$ reduction in dosage can be achieved when switching from intravenous to subcutaneous administration with no loss of effect. ${ }^{31}$ Stevens et al treated 12 patients receiving continuous ambulatory peritoneal dialysis with subcutaneous erythropoietin and obtained a brisk response to 300 or $450 \mathrm{U} / \mathrm{kg} /$ week (three doses). The dosage was then reduced to $37 \cdot 5-150 \mathrm{U} / \mathrm{kg}$ (median $75 \mathrm{U} / \mathrm{kg}$ ) weekly to maintain a haemoglobin concentration between 110 and $115 \mathrm{~g} / 1 .{ }^{32}$ The lowest total weekly dosage of erythropoietin reported to be effective to date was $98 \mathrm{U} / \mathrm{kg}$, given as a daily subcutaneous injection. ${ }^{33}$

Thus the subcutaneous route seems to be efficacious not only in patients receiving continuous ambulatory peritoneal dialysis ${ }^{2932}$ but also in those receiving haemodialysis,,$^{30}$ and the evidence to date suggests that lower doses of erythropoietin may be used when given by this route. Further studies are required, but on the evidence available a starting dose in the range of 25-75 U/kg given subcutaneously twice or thrice weekly seems suitable. If patients can be taught to give their own injections, then a daily dosing regimen ${ }^{33}$ may be worth considering.

\section{Target haemoglobin concentration}

The anaemia of chronic renal failure can be corrected fully with erythropoietin. In balancing the benefits and the risks, however, the common practice is to aim at partial correction. A linear increase in the haemoglobin concentration or packed cell volume leads to an exponential rise in the viscosity of whole blood, ${ }^{12-14}$ which, in turn, is thought to contribute to many of the side effects of treatment with erythropoietin such as hypertension, increased peripheral resistance, thrombotic complications, etc. In addition, this partial correction of the anaemia seems to cause near maximal improvement in wellbeing, exercise capacity, ${ }^{34}$ and symptoms of anaemia. A further increase in the haemoglobin does not confer any additional benefit ${ }^{3}$ and would therefore be less cost effective.

The target haemoglobin concentration most commonly used is in the range of $100-120 \mathrm{~g} / \mathrm{l}$, at which the ratio of risk to benefit seems to be minimised, though some flexibility is necessary in treating individua patients. Because the main aim of treatment with erythropoietin is to reverse the symptoms of anaemia differing thresholds at which this occurs may influence the appropriate final haemoglobin concentration.

With regard to the rate of rise of the haemoglobin 
response, for most patients an increase of $10 \mathrm{~g} / \mathrm{l} / \mathrm{month}$ seems sensible. Exceeding this limit may predispose the patient to an increased risk of side effects, and there is rarely any indication for more rapid correction of anaemia.

Impaired haemopoietic response to erythropoietin

The large multicentre trials of erythropoietin in the United States and Europe indicate that $95-98 \%$ of patients treated will respond. ${ }^{9}$ Nevertheless, there is undoubtedly a small proportion of patients who have either no response or a very inadequate one. Even though some of these patients will respond to a much higher dose of the hormone a precipitating cause should be sought (box). The most common problem is undoubtedly an inadequate supply of available iron, as discussed earlier. Other forms of haematinic deficiency, such as vitamin B-12 or folate, are less common and should have been excluded before starting treatment.

\section{Clinical algorithm for treating renal anaemia with erythropoietin}

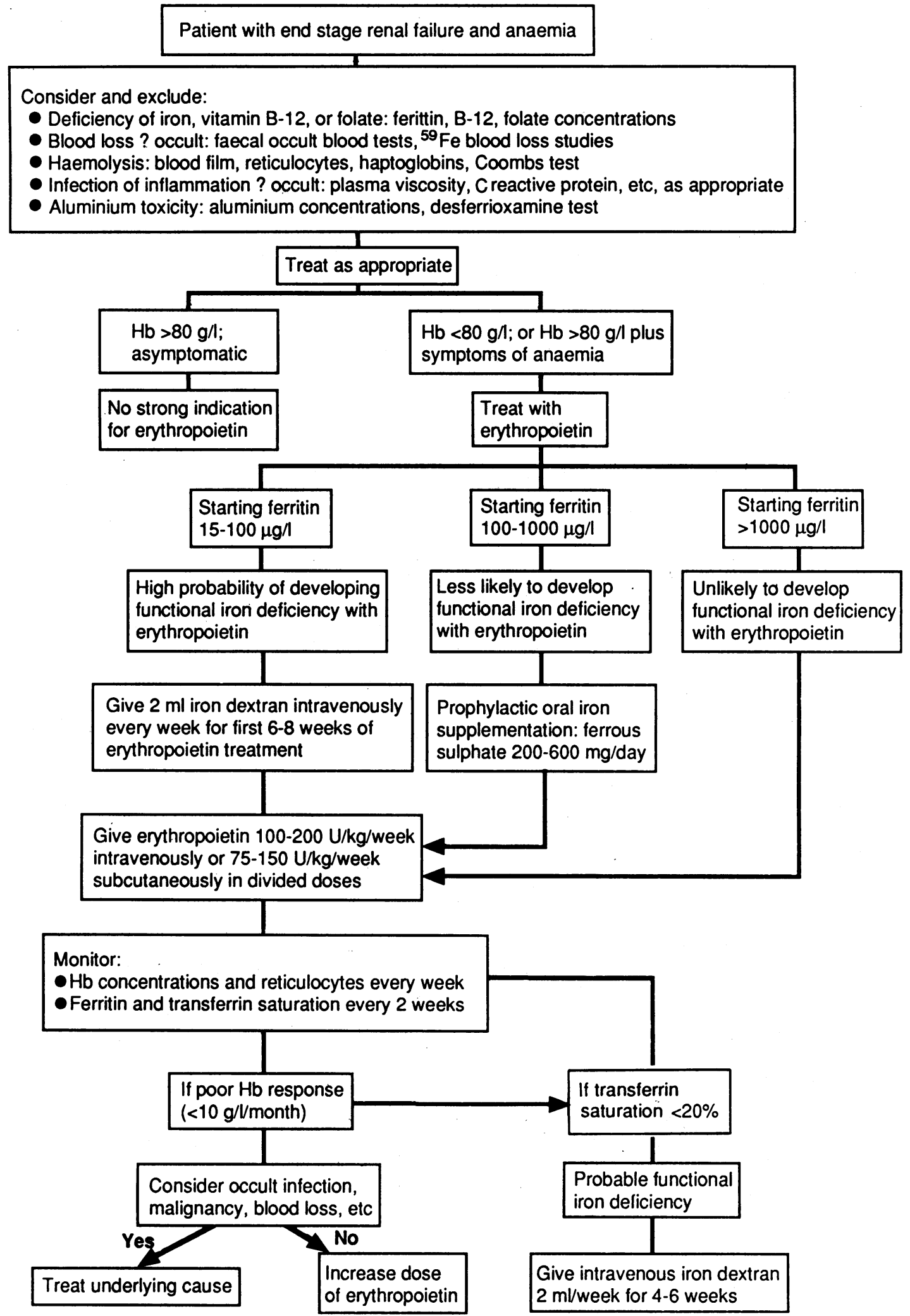




\section{Potential causes of erythropoietin resistance}

Decreased red cell production

- Iron deficiency

- B-12 or folate deficiency

- Aluminium toxicity

- Hyperparathyroidism with marrow fibrosis

- Infection:

acute

chronic

occult

- Malignancy: ?occult

- Poor absorption of erythropoietin (if given subcutaneously)

- Marrow dysfunction

- Red cell enzyme abnormalities - for example, pyruvate kinase deficiency.

Decreased red cell survival

- Blood loss: dialysis other, ?gastrointestinal tract, ?occult

- Haemolysis.

Aluminium toxicity is another cause of erythropoietin resistance, but a recent European multicentre trial showed that this must be severe before haemopoiesis is inhibited. ${ }^{36}$ High concentrations of parathyroid hormone inhibit erythropoiesis in vitro, ${ }^{37}$ but the clinical relevance of these findings remains controversial. ${ }^{36} 38{ }^{39}$ Infection, either acute or chronic, as well as occult malignancy are potent suppressors of erythropoietic activity, a feature observed by ourselves and others.

All these causes of erythropoietin resistance are examples of an inadequate haemopoietic response. The other possibility is that erythropoietin is effective in initiating increased erythropoietic activity but that there is also increased red cell loss through either haemolysis or blood loss. A clue to this may be an enhanced reticulocyte response that is not reflected in any change in the haemoglobin concentration. Formal quantitative investigation of blood loss may be required. It may be possible to override some of these causes of resistance to erythropoietin with a higher dose, but the importance of excluding them should not be disregarded.

\section{Potential complications}

A number of possible complications of treatment with erythropoietin have been described, including hypertension, ${ }^{56912}$ thrombosis of the arteriovenous fistula, ${ }^{578+0+1}$ flu-like symptoms, ${ }^{58+0}$ and increased plasma potassium concentrations before dialysis. ${ }^{68}$ Hypertension is most common and is potentially the most serious consequence of this treatment. It has been suggested that this is more common in patients with a previous history of a raised blood pressure,${ }^{8}$ but a large multicentre trial showed no greater risk of exacerbation of hypertension between patients who were previously hypertensive and those who were originally normotensive. ${ }^{42}$ It is therefore essential that arterial pressure is well controlled before starting treatment with erythropoietin and that the patient is monitored frequently. Although any increase in blood pressure can usually be controlled by hypotensive agents, ${ }^{42}$ a rise in blood pressure may be an indication for reducing the dose of the hormone with a consequent reduction in haemoglobin concentration. In other patients blood pressure control may be facilitated by aiming at a lower target haemoglobin concentration.

Thrombosis of the arteriovenous fistula was of some concern in the early studies of erythropoietin treatment, ${ }^{578}$ and a recent placebo controlled multicentre trial suggested that there is a significantly increased risk of this complication developing in patients receiving the hormone. ${ }^{41}$ Whether this is exacerbated by the increase in blood viscosity, ${ }^{12.14}$ changes in platelet function,,$^{+3-46}$ or a reduction in the concentrations of protein $\mathrm{C}$ and protein $\mathrm{S}^{47}$ requires further elucidation.

Flu-like symptoms have been recorded in a few patients early in the course of treatment, but these are of no consequence and disappear even if treatment is continued. ${ }^{5840}$ Genuine intolerance to erythropoietin sufficient to warrant stopping the hormone is rare. To date there has been no report of antibody formation. ${ }^{48}$

Some patients receiving haemodialysis are noted to have higher potassium and phosphate concentrations associated with an increase in packed cell volume. ${ }^{6}$ In some patients this may be due to increased dietary intake resulting from the general improvement in wellbeing. It is possible, however, that potassium clearance through the dialyser is lower with higher haemoglobin concentrations. ${ }^{49}$ Thus dietary guidelines should be reinforced for all patients starting erythropoietin treatment.

We thank Dr Frieda Houghton of Boehringer Mannheim UK Pharmaceuticals for support and encouragement with this work, and for supplying erythropoietin; and Miss Cheryl Patterson for expert secretarial assistance.

1 Eschbach JW, Adamson JW. Recombinant human erythropoietin: implica tions for nephrology. Am F Kidney Dis 1988;11:203-9.

2 Eschbach JW. The anaemia of chronic renal failure: pathophysiology and the effects of recombinant erythropoietin. Kidney Int 1989;35:134-48.

3 Winearls CG. Erythropoietin. Nephrol Dial Tranplant 1989;4:323-6.

4 Schaefer RM, Horl WH, Massry SG. Treatment of renal anemia with recombinant human erythropoietin. Am J Nephrol 1989;9:353-62.

Winearls CG, Oliver DO, Pippard MJ, Reid C, Downing MR, Cotes PM. Effect of human erythropoietin derived from recombinant DNA on the Eflec of human eryhropoietin derived from recombinant DNA on the 1986;ii:1175-8.

6 Eschbach JW, Egrie JC, Downing MR, Browne JK, Adamson JW. Correction of the anemia of end-stage renal disease with recombinant human rythropoietin. N Engl I Med 1987;316:73-8.

7 Bommer J, Alexiou U, Muller-Buhl E, Eifert J, Ritz E. Recombinant huma erythropoietin therapy in haemodialysis patients - dose determination an clinical experience. Nephrol Dial Transplant 1987;2:238-42.

8 Casati S, Passerini P. Campise MR, et al. Benefits and risks of protracted treatment with human recombinant erythropoietin in patients having haemodialysis. Br Med f 1987;295:1017-20

9 Eschbach JW, Downing MR, Egrie JC, Browne JK, Adamson JW. USA multicenter clinical trial with recombinant human erythropoietin (Amgen). Contrib Nephrol 1989;76:160-5.

10 DePaepe MBJ, Schelstraete KHG, Ringoir SMG, Lameire NH. Influence of continuous ambulatory peritoneal dialysis on the anemia of end-stage renal disease. Kidney Int 1983:23:744-8.

11 McGonigle RJS, Husserl F, Wallin JD, Fisher JW. Hemodialysis and continuous ambulatory peritoneal dialysis effects on erythropoiesis in rena Gilure. Kidney Int 1984:25:430-6.

12 Schaefer RM, Leschke M, Strauer BE, Heidland A. Blood rheology and hypertension in hemodialysis patients treated with erythropoietin. Am $\mathcal{F}$ Nephrol 1988;8:449-53.

13 Mayer G, Steffenelli T, Thum J, Cada EM, Stummvoll HK, Graf $\mathrm{H}$ Haemodynamic parameters and blood viscosity in the pathogenesis of erythropoietin treatment related hypertension. Nephrol Dial Transplant $1988 ; 3: 499$

14 Macdougall IC, Lewis NP, Saunders MJ, et al. Exercise capacity, fistula blood flow, and rheological studies during treatment with rHuEPO in haemodialysis patients. Nephrol Dial Transplant 1989;4:319.

15 Raine AEG. Hypertension, blood viscosity, and cardiovascular morbidity in renal failure: implications of erythropoietin therapy. Lancet 1988:i:97-100.

6. Lim VS, DeGowin RL, Zavaba D, et al Recombinant human erythropoietin treat $\mathrm{DeG}$ in pre-diassis patients: a double-blind placebo-controlled trial. treatment in pre-dialysis patien

17 Stone WJ, Graber SE, Krantz SB, et al. Treatment of the anemia of pre dialysis patients with recombinant human erythropoietin: a randomised placebo-controlled trial. Am $\mathcal{F}$ Med Sci 1988:296:171-9.

18 Eschbach JW, Kelly MR, Haley NR, Abels RI, Adamson JW. Treatment of the anemia of progressive renal failure with recombinant human erythropoietin. N Engl f Med 1989;321:158-63.

9 Caro J, Brown S, Miller O, Murray T, Erslev AJ. Erythropoietin levels in uremic nephric and anephric patients. F Lab Clin Med 1979;93:449-58.

20 Strickland ID, Chaput de Saintonge DM, Boulton FE, et al. A trial of oral iron in dialysis patients. Clin Nephrol 1974;2:13-7.

21 Strickland ID, Chaput de Saintonge DM, Boulton FE, Francis B, Ruobikova F, Waters JI. The therapeutic equivalence of oral and intravenous iron in renal dialysis patients. Clin Nephrol 1977;7:55-7.

22 Van Wyck DB, Stivelman JC, Ruiz J, Kirlin LF, Katz MA, Ogden DA Iron status in patients receiving erythropoietin for dialysis-associated anemia. Kidney Int 1989:35:712-6.

23 Macdougall IC, Hutton RD, Cavill I, Coles GA, Williams JD. Poor response to treatment of renal anaemia with erythropoietin corrected by iron given intravenously. Br Med f 1989;299:157-8. 
24 Cook JD, Skikne BS, Lynch SR, Reusser ME. Estimates of iron sufficiency in the US population. Blood 1986;68:726-31.

Bainton DF, Finch CA. The diagnosis of iron deficiency anemia. Am 7 Med $1964: 37: 62-70$

26 Macdougall IC, Roberts DE, Neubert $P$, Dharmasena AD, Coles GA, Williams JD. Pharmacokinetics of recombinant human erythropoietin in patients on continuous ambulatory peritoneal dialysis. Lancet 1989;i:425-7.

27 Boelaert JR, Schurgers ML, Matthys EG, et al. Comparative pharmacokinetics of recombinant erythropoietin administered by the intravenous, subcutaneous and intraperitoneal routes in continuous ambulatory peritoneal dialysis patients. Perit Dial Int 1989;9:95-8.

28 Frenken LAM, Coppens PJW, Tiggeler RGWL, Koene RAP. Intraperitoneal erythropoietin. Lancet 1988;ii:1495.

29 Macdougall IC, Cavill I, Davies ME, Hutton RD, Coles GA, Williams JD. Subcutaneous recombinant erythropoietin in the treatment of renal anaemia in CAPD patients. Contrib Nephrol 1989;76:219-26.

30 Macdougall IC, Roberts DE, Coles GA, Williams JD. Intraperitoneal erythropoietin. Lancet 1989;i:1389.

1 Bommer J, Ritz E, Weinreich T, Bommer G, Ziegler T. Subcutaneous erythropoietin Lancet 1988;ii:406.

32 Stevens JM, Strong CA, Oliver DO, Winearls CG, Cotes PM. Subcutaneous erythropoietin and peritoneal dialysis. Lancet 1989;i:1388-9.

33 Granolleras C, Branger B, Beau MC, Deschodt G, Alsabadani B, Shaldon S. Experience with daily self-administered subcutaneous erythropoietin. Contrib Nephrol 1989:76:143-8.

34 Mayer G, Thum J, Cada EM, Stummvoll HK, Graf H. Working capacity is increased following recombinant human erythropoietin treatment. Kidney Int 1988;34:525-8

35 Tsutsui M, Suzuki M, Hirasawa Y. Renewed cardiovascular dynamics induced by recombinant erythropoietin administration. Nephrol Dial Transplant 1989;4 (suppl): $146-50$

36 Grutzmacher P, Ehmer B, Messinger D, Scigalla P. Effect of aluminium overload and hyperparathyroidism on bone marrow response to recombinant human erythropoietin therapy. Nephrol Dial Transplant 1989;4:474.

37 Meytes D, Bogin E, Ma C, Dukes PP, Massry SG. Effects of parathyroid hormone on erythropoiesis. $\mathcal{f}$ Clin Invest 1981;67:1263-9.
$38 \mathrm{Hampl} \mathrm{H}$, Riedel E, Wendel G, Stabell U, Kessel M. Influence of parathyroid hormone on exogenous erythropoietin stimulated erythropoiesis in hemodialysis patients. Kidney Int 1988;33:224.

39 Fervenza F, Oliver DO, Forman E, Winearls CG. Autonomous hyperparathyroidism does not cause resistance to recombinant human erythropoietin. Nephrol Dial Transplant 1989;4:472.

40 Valderrabano $F$. Adverse effects of recombinant human erythropoietin in the treatment of anamia in chronic renal failure. Nephrol Dial Transplant 1988;3:503.

41 Canadian Erythropoietin Study Group. The clinical effects and side effects of recombinant human erythropoietin in anemic patients on chronic hemo dialysis. Clin Invest Med 1989;12 (suppl):B66.

42 Levin N. Management of blood pressure changes during recombinant human erythropoietin therapy. Semin Nephrol 1989;9 (suppl 2):16-20.

43 Moia M, Mannucci PM, Vizzotto L, Casati S, Cattaneo M, Ponticelli C. Improvement in the haemostatic defect of uraemia after treatment with recombinant human erythropoietin. Lancet 1987;ii:1227-9.

44 Van Geet C, Hauglustaine D, Verresen L, Vanrusselt M, Vermylen J. Haemostatic effects of recombinant human erythropoietin in chronic heamodialysis patients. Thromb Haemost 1989;61:117-21.

45 Dreyling KW, Steinhauer HB, Geiger H, Horl WH, Schollmeyer P. Platelet function under recombinant human erythropoietin therapy in haemodialysis patients. Nephrol Dial Transplant 1989;4:472.

46 Grutzmacher P, Bergmann M, Schoeppe W, Breddin K. Thrombocyte function and plasmatic coagulation under recombinant human erythropoietin therapy. Nephrol Dial Transplant 1989;4:473.

47 Macdougall IC, Davies ME, Hutton RD, Coles GA, Williams JD. Reduction in protein $C$ and protein $S$ levels after treatment with recombinant erythropoietin. Nephrol Dial Transplant 1989;4:476.

48 Watson AJ. Adverse effects of therapy for the correction of anemia in hemodialysis patients. Semin Nephrol 1989;9 (suppl 1):30-4.

49 Zehnder C. Erythropoietin treatment: influence of haemoglobin concentration on dialyser creatinine clearance in haemodialysed patients. Nephron 1989;51:424-5.

(Accepted 24 fanuary 1990)

\title{
Winter sports injuries in a snowless year: skiing, ice skating, and tobogganing
}

\author{
Alberic Fiennes, Gian Melcher, Thomas P Rüedi
}

From 1980 to 1989 an average of 150 million nights were spent in the Swiss Alps ${ }^{1}$ each winter by visitors, most of whom came to ski. In the past few years snowfalls have been late and scanty in many regions, and this year the problem has been even more severe than expected. Climatic variations affect the opportunities for winter sports and therefore the pattern and severity of injuries seen at local and regional hospitals. The same factors have also favoured the preparation of outdoor ice rinks, and in the absence of adequate skiing numerous visitors have turned to the ice as an alternative to a holiday of frustrated inactivity. Other tourists, perhaps believing themselves to be too cautious to skate, have taken to tobogganing.

\section{Skiing}

Case 1-A 19 year old woman with several years' skiing experience fell across her own ski sticks on hard terrain. She completed her descent but was later admitted to a primary hospital complaining of abdominal pain. Her circulation was stable under observation, but laparotomy was performed because of progressive peritoneal irritation. An extensive deep posterior laceration of the right lobe of the liver was débrided, an omental pedicle interposed, and the cavity packed. She subsequently required transfer to our hospital and second look laparotomy at three days, when the pack was removed and a $T$ tube placed in the common bile duct. After four days of intensive support and 14 days of hepatocellular type jaundice she made a full clinical and biochemical recovery, leaving hospital 21 days after the accident.

Case 2-On a crowded and icy piste a 22 year old man collided at speed with a skilift pylon. There was no obvious external injury or loss of consciousness, but progressive hypotension and tachypnoea prompted immediate evacuation by helicopter to our centre. On arrival he had a patent airway, shallow respiration
( $>36 / \mathrm{min}$ ), and central pulses only. Initially semiconscious and agitated, he quickly had a cardiac arrest. In the course of resuscitation immediate laparotomy showed a ruptured liver and diaphragm but little blood. At median sternotomy there was no pericardial tamponade and an empty heart was noted. The right lower lobe vessels and bronchus were found to be avulsed, and resuscitation proved to be impossible.

\section{Ice skating}

Case 3-Following the closure of local ski lifts a 48 year old physically active man was skating on a heavily used village ice rink when his left skate engaged in a deep crevice left by the previous day's skaters. He fell to one side, sustaining a simple short spiral fracture of the tibial isthmus and fibular neck. He was treated at our hospital four hours after injury by open reduction and low contact dynamic compression plating ${ }^{2}$ through an anterolateral approach. Five days later he was discharged partially weightbearing and able to return to his native country by road.

Case 4-An active 68 year old woman hankered after the skating agility of her younger days. On a left turn her poorly sharpened skates slid from under her and she fell on to her left hip. She was helped to her feet and hobbled off the rink in considerable pain, which later drove her to come to our hospital. $x$ Ray films confirmed an impacted subcapital femoral fracture. The fracture position was acceptable, and she was treated by analgesia and carefully supervised mobilisation, being discharged to a rehabilitation unit after 11 days.

Case 5-Prevented by poor local conditions from skiing, a transatlantic visitor of 60 was enjoying a friendly curling match. Enthused by success, he ran up the rink in chase of his winning stone. Turning rapidly to announce victory to his companions, he slipped and fell face forward, sustaining a basal skull fracture, right
Correspondence to: $\mathrm{Mr}$ Fiennes.

BrMed J 1990;300:659-61 